\title{
Paradoxes of Portfolio Performance Calculation for Wealth Management: Avoiding Reporting Pitfalls
}

\author{
Claude Diserens' ${ }^{1}$, Emmanuel Fragnière ${ }^{2}$, Christophe Holenstein ${ }^{1}$, Stephen Rufino ${ }^{1}$ \\ ${ }^{1}$ Galeo, RiskLab, Boulevard Georges-Favon 19, Geneva, Switzerland \\ ${ }^{2}$ University of Applied Sciences Western Switzerland, Sierre, Switzerland \\ Email: galeo@galeo.ch,emmanuel.fragniere@hevs.ch
}

How to cite this paper: Diserens, C., Fragnière, E., Holenstein, C., \& Rufino, S. (2018). Paradoxes of Portfolio Performance Calculation for Wealth Management: Avoiding Reporting Pitfalls. Journal of Financial Risk Management, 7, 205-222. https://doi.org/10.4236/jfrm.2018.73014

Received: August 20, 2018

Accepted: September 18, 2018

Published: September 21, 2018

Copyright $\odot 2018$ by authors and Scientific Research Publishing Inc. This work is licensed under the Creative Commons Attribution International License (CC BY 4.0).

http://creativecommons.org/licenses/by/4.0/

\begin{abstract}
Clients of wealth management banks are usually informed about their portfolio through regular reporting. To maintain client trust, it is important that this reporting be both comprehensive and comprehensible. This reporting is grounded on complex mathematics in order to calculate myriads of profit and loss, performance and risk indicators. As the amount of information provided to clients increases so does the chance that certain elements will be confusing to them, at the risk of undermining their confidence in their wealth management bank. This risk is compounded by the general increase in portfolios of complex financial products involving different time horizons. The reporting is typically a decision aid tool for the client to monitor and control and make investment decisions. One example of such risk is that the calculated risk and performance indicators are delivered to the client with no explanation and can, in some cases, lead to incorrect perception due to misunderstanding of these numbers, even if calculations are correct. A typical example could be that the client is informed that the performance of the portfolio is $7 \%$ and in reality, the portfolio is losing money. In this paper, we want to address this kind of problem. As such we have identified a set of typical pitfalls that we are faced within the profession. Then, based on a rigorous reference to the scientific literature we have popularized these pitfalls and employed a series of simple and didactic illustrations to provide an appropriate toolbox in order to reduce the risk of financial reporting misunderstanding. In order to maintain client confidence, we highlight the importance of identifying areas of potential misunderstanding prior to providing reports to clients and of offering clear explanations for unusual numbers. We address the following themes: Profit and Loss Analysis, Performance Calculation, Performance Contribution, Realized and Unrealized Profits and Losses, and Bond Yields.
\end{abstract}




\section{Keywords}

Client Trust, Financial Reporting, Portfolio Performance, Portfolio Profit and Loss, Wealth Management

\section{Introduction}

"Wall Street, it seems, simply cannot be trusted."

Stephen Foley, The Independent, January 29, 2009

In December 2008, as the economic crisis continued on its devastating course, a scandal broke. On the night of the 11 th, the FBI made a call at 8:30 pm. As they were waiting for the elevator they could not have realized that they were about to unmask the greatest fraudster the world has ever seen. A fraud amounting to US $\$ 50$ billion was uncovered through the confession of its perpetrator: the boy from Queens, New York, Bernard L. Madoff. The 70-year-old financier was conning his family, friends, colleagues and clients.

Needless to say, the unprecedented scope of the fraud was beyond the reach of other scandals of the financial system, a system in such a bad shape that clients came to question their trust in it. Madoff never killed anyone, but the pain he left in his fall is huge: the global destruction of clients' trust in the financial system and traditional firms. How can such trust be restored?

Since the financial crisis of 2008, clients' confidence in the financial system and in banks in particular has declined. Helped by improvement in technology, banks and wealth managers have attempted to reverse this erosion of client trust by offering higher transparency in the form of more complete reporting. However, these bank statements are not easy to understand and clients often don't have the maturity or the skills to apprehend such complicated reports that lack clarity. Such sophistication in reporting risks back-firing as clients struggle to comprehend the information contained in their reports which they will view with growing suspicion. It is important to avoid client confusion in order to maintain their trust. This is when independent wealth reporting is important and displays its value. The pain felt by clients is real and needs to be addressed.

In this paper, we will highlight through various paradoxes how you can popularize the KPIs (Key Performance Indicators) often discussed by bankers and wealth managers but that are potentially baffling to their clients. Understanding unusual numbers can be difficult to the untrained eye. When you add to that a homogenized reporting created by the need to cut personnel in the bank industry, it leads to new needs for reporting with a customized explanation by trained and reliable professionals. The digitalization of bank back-offices creates new needs for reporting as well; for example, the consolidation of reporting from different sources. The end goal is, of course, serving clients with accurate reporting.

The authors of this paper, as academics and professionals of financial reporting, have had the opportunity to spot a series of pitfalls and we intend to popu- 
larize the most important ones. To our knowledge this work has not been done yet in the scientific community and thus represents a contribution in terms of risk protection for the clients of wealth management.

The research question of this paper is then: How can we popularize client reporting pitfalls through simple illustration examples?

Portfolio performance calculation for wealth management can be very complicated for the laymen and consequently for clients of banks. In this paper, we want to demystify some important issues related to portfolio performance calculation with the aim that clients will be able to in the future better understand what is contained in the financial reporting they received from their bank. In the following brief literature review, we would like to provide several references that pursue the same goal: making financial reporting accessible to everybody. We believe this is the first important measure of risk management. In general, the books or articles suggested are complex since they integrate high-level mathematics. Nevertheless, there are of excellent quality. The first ones we mention are related to general performance calculation (Christopherson et al., 2009; Tyson, 1999; Grinold \& Kahn, 2000). Then there are more specific calculations like the Dietz-weighted performance (Bacon, 2008; Feibel, 2003; Le Sourd, 2007). For references about consolidated portfolio performance we can suggest (Brealey et al., 1995; Reilly \& Brown, 1997). Performance attribution represents a topic on its own in terms of portfolio performance and many texts exist (see Brinson et al., 1986, 1991). Finally, all the literature on bonds and interest rate calculations are usually very specialized on this theme (Homer \& Leibowitz, 1972; Smith, 2011).

The significance of this research is to simplify elements of reporting that are usually not explained and grounded on complex mathematics. Its practical value is that it can be of help to students and practitioners to improve their reading skills of financial reporting. And moreover, its academic significance is to indicate to researchers some issues faced by clients of wealth management banks and to encourage them to investigate them.

The text is organized as follows. In Section 2, we present the general concepts of portfolio profit and loss and of portfolio performance and provide an example where these two simple measures may seem contradictory to a client. In Section 3 , we explore the impact of cash flows on portfolio performance calculation and detail the various methodologies for dealing with them. We illustrate the complexities introduced by capital movements with several examples and suggest approaches to minimize client confusion. In Section 4, we detail the methodologies for consolidating portfolio performance as well as those for breaking down portfolio performance into that of hypothetical sub-portfolios, particularly in the presence of loans. We illustrate these calculations in several situations that appear confusing. In Section 5, we shift our attention from portfolio performance to position performance. We have chosen a few themes with which to illustrate this very broad topic. For each of these subjects we provide examples of confusing results that risk decreasing a client's trust in the reporting she/he receives. In 
Section 6, we conclude and provide direction for further research.

\section{From Portfolio Profit and Loss to Performance}

In this section, we will introduce the concepts of portfolio profit and loss and of portfolio performance. With an example, we will illustrate a situation where these two simple measures may appear incoherent and confusing to a client at the risk of diminishing his confidence in the reporting provided to him.

\subsection{Profit and Loss Plain and Simple}

Calculating a portfolio's profit and loss $(\mathrm{P} \& \mathrm{~L})$ can be cumbersome as capital flows, price changes, interest and fees accruals, tax withholdings and foreign exchange rates that all need to be taken into account. The formula is, however, simple: change in value reduced by net capital flows contributed. Let us illustrate with a portfolio holding a single position and a cash account.

Example for an investment in a position (see Figure 1)

2 shares are bought at a price of 50 each plus a total fee of 5 . The share price then falls to 45 and 1 share is sold at a cost of a fee of 5 . Finally, the share price rises to 60 (see Figure 1).

Gross $\mathrm{P} / \mathrm{L}=60-55=5$

Net $\mathrm{P} / \mathrm{L}=60-65=-5$, including fees of 10

Example for the cash account used to buy the 2 shares (see Figure 2)

The account initially received 150 minus a fee of 5. During the period, 105 were used to buy two shares and 40 were received from the later sale of one share. At the end of the period 20 were withdrawn at a cost of 5 (see Figure 2).

Gross $\mathrm{P} / \mathrm{L}=55-120-(-65)=0$

Net $\mathrm{P} / \mathrm{L}=55-130-(-65)=-10$, including fees of 10

Example for the combined portfolio (see Figure 3)

Gross $\mathrm{P} / \mathrm{L}=115-120-(-10)=5$

Net $\mathrm{P} / \mathrm{L}=115-130=-15$, including fees of 20

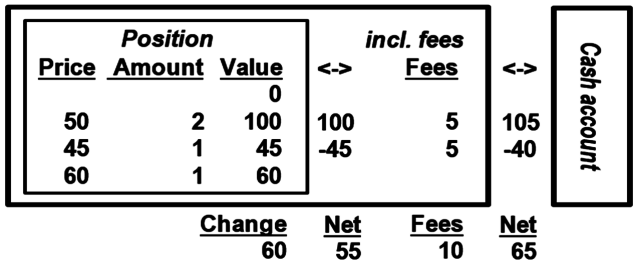

Figure 1. Profit and loss for a single position.

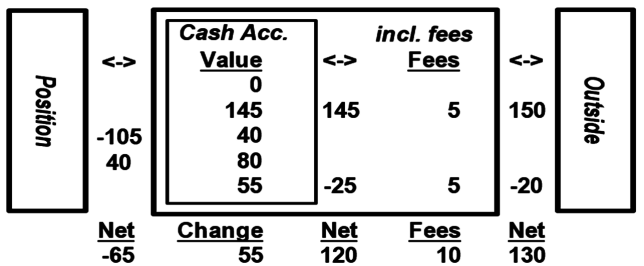

Figure 2. Profit and loss for a cash account. 


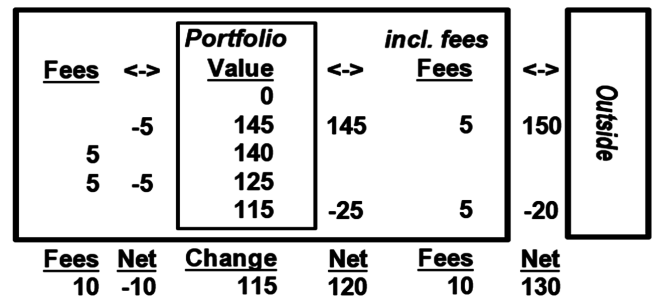

Figure 3. Profit and loss for a portfolio combining a cash account and a single position.

The P/Ls of the position (Goss 5; Net -5 ) and the cash account (Gross 0; Net -10 ) add-up perfectly to the P/Ls of the portfolio as a whole (Gross 5; Net -15).

\section{Findings and recommendations}

While it is tempting to explain a portfolio's $\mathrm{P} \& \mathrm{~L}$ from the aggregation of the performance of its individual holdings it is much simpler to use the formula: change in value reduced by net capital flows contributed.

The P \& L of individual holdings can be derived in the same manner and will add up to that of the portfolio.

\subsection{Portfolio Performance}

The performance of a portfolio over a period during which no capital flows occur is defined simply as the change in value of the portfolio divided by the portfolio's value at the start of the period.

$$
\text { Performance }=\left(V_{\mathrm{END}}-V_{\mathrm{START}}\right) / V_{\mathrm{START}}=V_{\mathrm{END}} / V_{\mathrm{START}}-1
$$

The performance for two successive periods can be calculated from the performances of the individual periods by their compounding as long as capital flows only occur between the two periods:

$$
\operatorname{Perf}_{t}=\left(1+\operatorname{Perf}_{1}\right) \times\left(1+\operatorname{Perf}_{2}\right)-1=\left(V_{\mathrm{END} 1} / V_{\mathrm{START} 1}\right) \times\left(V_{\mathrm{END} 2} / V_{\mathrm{START} 2}\right)-1
$$

where $V_{\text {START2 }}=V_{\text {END1 }}+$ inflows - outflows.

While the fundamentals of portfolio performance calculation are straightforward they can be the source of many apparent paradoxes. A simple example is that of a portfolio displaying a positive period performance but a negative $\mathrm{P} \& \mathrm{~L}$. The explanation for such a conundrum is to be found, as is often the case, in the capital flows.

\section{Example}

A portfolio of 1000 with an outflow of 500 midway through the period loses $10 \%$ in the first half of the period and then gains $20 \%$ in the second half for a total performance of $8 \%$.

$$
\text { Performance }=(1-10 \%) \times(1+20 \%)-1=8 \%
$$

At the end of the first half, following the $10 \%$ loss, which corresponds to a decrease in value of 100 , the portfolio was worth 900 . After the outflow of 500, the portfolio started the second half with a value of 400 on which a gain of $20 \%$, equivalent to 80 , was made to finish the period with a worth of 480 . Considering the withdrawal of 500 the total final value to the portfolio's holder was 980 . 


$$
P \& L=(480+500)-1000=980-1000=-20
$$

So, while the portfolio manager may be satisfied with his $8 \%$ performance, the portfolio's holder will be disappointed by the loss she/he has incurred. This divergence in perception is due to the outflow of 500 which may have been an unsuccessful investment decision by the portfolio's holder or may just as well have been motivated by the holder's need for cash.

\section{Findings and recommendations}

Capital flows can result in a client's personal experience differing from the calculated portfolio performance. Such situations are sensitive and need to be approached with caution as the portfolio's $\mathrm{P} \& \mathrm{~L}$ is the result of a combination of the portfolio manager's investment choices and the client's capital flows decisions, which may be driven by factors other than pure portfolio performance optimization.

\section{Details of Portfolio Performance Calculation}

In this section, we will explore the impact of cash flows on portfolio performance calculation and will detail the methodologies for dealing with them. We will provide several examples to illustrate the pitfalls introduced by capital movements and suggest how best to present such cases to clients.

\subsection{Modified Dietz versus Time-Weighted Performance}

In the presence of cash flows the calculation of portfolio performance becomes a disputed issue. The two main approaches are: money-weighted and time-weighted. The first estimates an internal rate of return (IRR) matching the portfolio start value, cash flows and end value over a specified time frame. The second calculates sub-period returns, thus isolating cash flows, and compounds these into the period return.

In the presence of a cash flow the Modified Dietz is calculated as follows

$$
\left(V_{\mathrm{END}}-V_{\mathrm{START}}-C F\right) /\left(V_{\mathrm{START}}+W \times C F\right)
$$

where $V_{\mathrm{START}}$ and $V_{\mathrm{END}}$ are the portfolio's start and end values, $C F$ the cashflow contribution and $W$ the remaining period fraction at the time of the cash flow.

\section{Example}

In first half of 2015 a portfolio of 1000 ( $\left.V_{\text {START }}\right)$ loses $10 \%$. The client at once withdraws $700(C F, W=0.5)$ after which the portfolio recovers $20 \%$ to finish the year at $240\left(V_{\text {END }}\right)$.

Money-weighted-Modified Dietz

$$
\begin{aligned}
& \left(V_{\mathrm{END}}-V_{\mathrm{START}}-C F\right) /\left(V_{\mathrm{START}}+W \times C F\right) \\
& =(240-1000+700) /(1000-700 \times 0.5)=-60 / 650=-9.2 \%
\end{aligned}
$$

Time-weighted

$$
(1-10 \%) \times(1+20 \%)-1=8 \%
$$

What a difference! The time-weighted return measures the portfolio manag- 
er's performance but requires portfolio values at each cash flow. The less onerous Modified Dietz calculation combines manager performance with client allocation decisions to obtain an estimated internal rate of return (IRR) and is as such not a pure measure of manager ability but it often better reflects client satisfaction, which in the above example would be poor.

\section{Findings and recommendations}

The choice of a performance calculation methodology will depend on multiple factors including regulatory requirements, system capabilities and reporting frequency. A Modified Dietz methodology may better reflect client experience but it will be less appropriate for portfolio management performance analysis. Independent of the methodology chosen it is important to monitor the discrepancies between the calculated performance measure and the client's perceived performance.

\subsection{Compounding Portfolio Returns}

The Modified Dietz method provides an estimate of a portfolio's internal rate of return that takes inflows and outflows into account. In the presence of multiple cash flows it is calculated as follows:

$$
\left(V_{\mathrm{END}}-V_{\mathrm{START}}-\sum C F_{i}\right) /\left(V_{\mathrm{START}}+\sum W_{i} \times C F_{i}\right)
$$

with $V_{\text {START }}$ and $V_{\text {END }}$ the portfolio's start and end values, $C F_{i}$ the cashflows and $W_{i}$ the remaining period fraction (i.e., remaining days in period/period length in days).

\section{Example}

A portfolio, worth 100 at the end of 2015, grows by $20 \%$ to mid-year. After an inflow of 30 its value falls by a third (see Table 1 ).

Modified Dietz return: $(100-100-30) /(100+15)=-26.1 \%$

This differs from the portfolio's compounded time-weighted performance of $-20 \%$ due to the long period, large inflow and volatile performance.

The portfolio loses $10 \%$ in the first 4/5th of 2017 and then, after an outflow of 10 , gains $25 \%$ to year-end (see Table 2 ).

Table 1. Time-weighted and modified Dietz performance calculations for a single period.

\begin{tabular}{ccccccc}
\hline Date & Time-weighted Performance & Compounded & $V$ & $C F$ & $W$ & $W^{*} C F$ \\
\hline $31 / 12 / 15$ & & & 100 & & 1 & \\
$01 / 07 / 16$ & $20 \%$ & $20 \%$ & 150 & 30 & 0.5 & 15 \\
$31 / 12 / 16$ & $-33 \%$ & $-20 \%$ & 100 & & 0 & \\
\hline
\end{tabular}

Table 2. Time-weighted and modified dietz performance calculations for a second period.

\begin{tabular}{ccccccc}
\hline Date & Time-weighted Performance & Compounded & $V$ & $C F$ & $W$ & $W^{*} C F$ \\
\hline $31 / 12 / 16$ & & & 100 & & 1 & \\
$19 / 10 / 17$ & $-10 \%$ & $-10 \%$ & 80 & -10 & 0.2 & -2 \\
$31 / 12 / 17$ & $25 \%$ & $12.5 \%$ & 100 & & 0 &
\end{tabular}


Modified Dietz return: $(100-100+10) /(100-2)=10.2 \%$ versus a $12.5 \%$ timeweighted performance.

For the two years in aggregate the result is the following (see Table 3).

Modified Dietz return: $(100-100-20) /(100+21.5)=-16.5 \%$ versus a $-10 \%$ time-weighted performance.

Not only does the aggregated two-year Modified Dietz return differ from the portfolio's cumulative time-weighted performance of $-10 \%$ but it also differs from the compounded 2016 and 2017 Modified Dietz returns:

$$
(1-26.1 \%) \times(1+10.2 \%)-1=-18.5 \%
$$

The Modified Dietz method does not require portfolio valuations at the time of each cash flow, only at the period start and end and, as mentioned in the previous section, it may better reflect a client's perceived performance. It is, however, sensitive to the length of the calculation period, significant flows and volatile performances. For these reasons it is usually calculated on a monthly or quarterly basis and then compounded to obtain the return for longer periods. This compounding of Modified Dietz returns may itself result in discrepancies between the calculated performance and the client's perceived performance, specifically when the client is observing periods of a longer time frame than that used to calculate Modified Dietz returns.

\section{Findings and recommendations}

The Modified Dietz method lacks internal coherence in that it may not be possible to derive precisely the Modified Dietz performance of a period from that of its sub-periods. To avoid introducing additional confusion to performance reporting it is necessary to derive the performance of long periods by compounding the Modified Dietz performances of their shorter sub-periods, which preferably should match the reporting frequency. The results obtained with this methodology will more closely match those derived using time weighed calculations. But no solution can perfectly bridge the gap between client perception and the effective portfolio performance.

\subsection{Performance and the Intraday Timing of Cashflows}

With the knowledge of a portfolio's end of day values and the dates of its cashflows one can calculate the portfolio's performance by compounding its daily performances. The determination of daily performances requires an assumption

Table 3. Time-weighted and modified dietz performance calculations for combined periods.

\begin{tabular}{ccccccc}
\hline Date & Time-weighted Performance & Compounded & $V$ & $C F$ & $W$ & $W^{*} C F$ \\
\hline $31 / 12 / 15$ & & & 100 & & 1 & \\
$01 / 07 / 16$ & $20 \%$ & $20 \%$ & 150 & 30 & 0.75 & 22.5 \\
$19 / 10 / 17$ & $-40 \%$ & $-28 \%$ & 80 & -10 & 0.1 & -1 \\
$31 / 12 / 17$ & $25 \%$ & $-10 \%$ & 100 & & 0 & \\
\hline
\end{tabular}


about when precisely during the day cashflows should be considered to have taken place: at the beginning, the end or in the middle?

We will illustrate the determination of daily performance using the Modified Dietz method, which is calculated as follows:

$$
\left(V_{\mathrm{END}}-V_{\mathrm{PRIOR}}-C F\right) /\left(V_{\mathrm{PRIOR}}+C F \times W\right)
$$

with $V_{\mathrm{PRIOR}}$ and $V_{\mathrm{END}}$ the portfolio's values at the end of the prior and current days, $\mathrm{CF}$ the cashflow and $\mathrm{W}$ the remaining day fraction. For example, if a cashflow occurs at start of day $W=1$ and if the cashflow occurs at end of day $W=0$.

Example-end of day with $W=0$

A client opens an account with a contribution of 100. The bank takes a fee of 10 leaving 90 in the client's account. Considering the credit entry to have taken place at the end of day would imply a division by zero as:

$$
W=0 \text { and }\left(V_{\text {PRIOR }}+C F \times W\right)=(0+100 \times 0)=0
$$

This problem can be solved by assuming the credit entry occurred at start of day as $W=1$ and the Modified Dietz return is:

$$
(90-0-100) /(0+100 \times 1)=-10 / 100=-10 \%
$$

\section{Example-start of day with $W=1$}

Unhappy with his bank's fees, the client decides to close his account. The bank takes a further fee of 9 and wires the remaining 81 to the client. Considering the payment to have taken place at the start of the day results in $W=1$ and a daily Modified Dietz return of:

$$
(0-90+81) /(90-81 \times 1)=-9 / 9=-100 \%
$$

This is plainly wrong and the expected performance is derived by assuming the payment occurred at end of day:

$$
(0-90+81) /(90-81 \times 0)=-9 / 90=-10 \%
$$

What about cashflows other than opening and closing flows? A possibility is to consider that all inflows occur at start of day and all outflows at day end. This may result in an unexpected performance impact if a large sum of money momentarily transits through an account. Another alternative is to consider that, with the exclusion of opening and closing flows, all flows occur in the middle of the day.

\section{Findings and recommendations}

It is necessary to define a detailed methodology for the intraday timing of cash flows with the knowledge that it will not be perfect in all situations. For example, using the convention that inflows occur at start of day and outflows at end of day suggests that in the case of an inter account transfer the credit entry occurs before the outgoing payment! When the chosen methodology leads to results that differ from the client's own perception or understanding it is important to be able to offer him a simple and coherent explanation to avoid him losing his trust in the reporting provided to him. 


\section{Portfolio Consolidation and Breakdown}

In this section we will present the methodology for deriving the performance of consolidated portfolios and that for breaking down the performance of a portfolio into the performance of it parts particularly in the presence of loans. We will use several sample cases to exemplify the issues that can arise with these calculations.

\subsection{Consolidated Portfolio Performance}

Given the performances of two portfolios, what additional information is required to calculate their consolidated time-weighted performance? In the absence of external flows, the value of the portfolios at start of the period is sufficient.

Example 1

Portfolio A of value 100 achieved a performance of $10 \%$ over the period $\mathrm{P}_{1}$ to finish with a value of 110 . Portfolio $B$ is one and a half times the size and lost $10 \%$ to finish at 135 . Their consolidated $\mathrm{P}_{1}$ performance is therefore:

$$
-2 \%=(10 \% \times 100-10 \% \times 150) / 250
$$

In the presence of capital flows, additional information is required consisting of the flow amounts and the value of the two portfolios at the time the flows occur.

Example 2

At the end of the $\mathrm{P}_{1}$ period 70 flows out of Portfolio B and into Portfolio A. In the following $\mathrm{P}_{2}$ period portfolios $\mathrm{A}$ and $\mathrm{B}$ perform respectively $-5 \%$ and $15 \%$, resulting in a consolidated performance of:

$$
(-5 \% \times(110+70)+15 \% \times(135-70)) /(110+135)=0.31 \%
$$

Compounding provides the combined $\mathrm{P}_{1}$ and $\mathrm{P}_{2}$ period consolidated performance of:

$$
(1-2 \%) \times(1+0.31 \%)-1=-1.7 \%
$$

A negative consolidated performance when both portfolios actually performed positively over the two periods combined:

$$
\begin{gathered}
\mathrm{P}_{1}:(1+10 \%) \times(1-5 \%)-1=4.5 \% \\
\mathrm{P}_{2}:(1-10 \%) \times(1+15 \%)-1=3.5 \%
\end{gathered}
$$

In the generalization to the consolidation of multiple portfolios it is reasonable to assume flows may occur on any day. It is therefore necessary to know the daily values of each portfolio as well as their flows to calculate their daily consolidated performances. Compounding these daily performances over a period provides the consolidated time-weighted performance for the period.

Assuming flows occur midday, consolidated daily performances can be calculated as follows:

$$
\left(V_{\mathrm{END}}-\text { Flows } / 2\right) /\left(V_{\mathrm{PRIOR}}+\text { Flows } / 2\right)-1
$$


In the absence of flows, compounding daily performance can be simplified and only initial and final values are required:

$$
\left(V_{1} / V_{0}\right) \times\left(V_{2} / V_{1}\right) \times \cdots \times\left(V_{n} / V_{n-1}\right)-1=\left(V_{n} / V_{0}\right)-1
$$

In the presence of flows this simplification is impossible as the intermediary terms cannot be eliminated.

\section{Findings and recommendations}

The consolidation of portfolio performance may lead to results that a client may find surprising. Such discrepancies are delicate issues as they likely result from the client's capital flows decisions, which may be driven by factors other than pure portfolio performance maximization.

\subsection{The Impact of Loans}

It is not uncommon for portfolios to hold investment positions and loans. A loan may be used to increase the value of the investments or for another purpose with the investments acting as a guarantee for the loan. The loan's presence will impact the portfolio's performance. In the absence of a loan a portfolio's time-weighted performance represents both the net performance of its investments and that achieved by its owner. This is no more the case in the presence of a loan where a portfolio's performance does not provide a true assessment of an investment manager's quality.

\section{Example 1}

Portfolio A of size 100 achieved a performance of $10 \%$ over the year. Portfolio $B$ is half the size but due to a loan of 50 at a cost of $3 \%$ is able to hold identical investments to portfolio A. While portfolio B's investments will have achieved $10 \%$ over the year, the portfolio itself will have gained $17 \%$ due to the leverage:

$$
(100 \times 10 \%-50 \times 3 \%) / 50-1=17 \%
$$

To determine the performance achieved by the investments in a portfolio containing loans the portfolio is separated into two hypothetical portfolios, one holding the investments and one the loans. Interest payments are transferred out of the investment portfolio without altering its performance and are paid from the loan portfolio with a performance impact.

\section{Example 2}

Portfolio B of size 50 is split into portfolio I (nvestment) of 100 and portfolio $\mathrm{L}$ (oan) of -50 . Assuming interest payments occur on close of last day of the year, portfolio I will have grown by $10 \%$ to 110 of which 1.5 will be transferred to portfolio L, which will have decreased to -51.5 for a performance of $3 \%$. Consolidating the two portfolios gives a final value of $108.5-50=58.5,17 \%$ above the starting value of 50 . The performance calculations for the hypothetical loan portfolio bring up issues which will be illustrated in the next section.

\section{Findings and recommendations}

The presence of loans in an investment portfolio complicate the determination of the portfolio manager's performance and increase the likelihood that 
client perception and manager performance diverge. Extracting the loans from the portfolio allows for a better assessment of manager performance but adds the challenge of explaining the performance of the isolated loan to the client.

\subsection{The Negatives of Negative Values}

While not very common, portfolios can have negative net asset values as a result of poor performance, typically in the presence of loans or derivatives with collateral held outside the portfolio. In such circumstances performance analysis may yield unexpected results. Here are a few examples starting with performance annualization.

\section{Example of performance annualization}

What is the annualized performance of a portfolio valued at 100 at the start of the year that declines by $110 \%$ to -10 by the end of August? The calculation is simple:

$$
\left(V_{\text {end }} / V_{\text {start }}\right)^{\text {Length year/Length period }}-1
$$

but impossible to perform in real number space as it involves the square root of a negative number:

$$
(-10 / 100)^{12 / 8}-1=-0.1^{3 / 2}-1=-0.001^{1 / 2}-1
$$

Performance compounding can also be an issue for a portfolio whose net asset value turns negative as it must have been worth zero at some point in time.

Example of performance compounding

Let us use the previous example and in addition consider that the portfolio's net asset value stood at zero end of April. To end April the portfolio lost 100\% but its performance from end of April is undetermined as its calculation involves dividing by zero. Compounding the two periods is impossible even if the result is known to be $-110 \%$ !

Another issue is the interpretation of performance numbers once a portfolio's net asset value is negative.

Example of performance interpretation when portfolios' net assets are negative

Assuming the portfolio's net asset value was -1 end of May, -10 end of June and 10 end of July, what are the monthly performances for June and July? June's is $(-10 /-1-1)=900 \%$ a positive return while portfolio value actually fell over the month from -1 to -10 . That of July is $(10 /-10-1)=-200 \%$ while the portfolio's value rose from -10 to 10 .

To understand, consider that a portfolio with a negative net asset value holds a short position in an asset whose performance is being measured. While this approach allows for making sense of performance numbers and permits the compounding of performances it is difficult to grasp for clients and presents difficulties when indexing track records.

Example of indexing

To compare, on the same graph, the performance of the portfolio from end of 
May to end of August to that of other portfolios, all the compared portfolios are indexed by first assuming that they start the period with a value of 100 and then applying their respective performances starting from this value of 100 . The portfolio was valued at -1 end of May, fell to -10 by end of June then rose to 10 by end of July before falling back to -10 by end of August. Indexing the portfolio results in the following series:

May 100; June 1000; July -1000; August 1000.

This is the complete opposite of development of the portfolio's value during the period:

May -1 ; June -10 , July 10; August -10 .

While mathematically correct, such an indexed graph will leave not only the client but also investment professionals thoroughly confused. An option to side-step such pitfalls is to inverse the performance sign when the start value, $\mathrm{V}_{\text {start }}$, is negative and then when indexing to inverse the performance if the index value to which it is applied is negative. Such a calculation method would result in the more comprehensible performance and indexed series:

Performance: June $-900 \%$; July $200 \%$; August $-200 \%$,

Indexed: May 100; June -800 ; July 800; August -800 .

\section{Findings and recommendations}

The reporting of the performance of portfolios with negative asset values presents many challenges. While the methods presented above allow for certain of these issues to be circumvented, it is recommended to provide the client with didactic guidance in the interpretation of the results of portfolios with negative asset values.

\section{Position Performance}

In this section we will shift from portfolio performance issues to those of position performance. As the topic is very broad we have chosen a few themes with which to illustrate it: position contribution, realized and unrealized profits and bond yields. For each of these subjects we provide example cases which lead to confusing results and therefore risk decreasing the client's trust in the reporting provided to him.

\subsection{Position Percentage Contribution}

In the imaginary world of static portfolios, calculating a position's percentage contribution is simple.

\section{Example 1}

A portfolio is composed of two positions, A and B, equally weighted where A gained $12 \%$ and $B$ lost $1 \%$. The contribution of $A$ is $6 \%=50 \% * 12 \%$ and that of $\mathrm{B}$ is $-0.5 \%=50 \%{ }^{*}-1 \%$. Adding the contributions of both positions gives the portfolio's performance as $5.5 \%$.

In the presence of an intra period transaction, using the start of period weights is unsuitable. A solution could be to split the period at transaction time, 
calculate the contributions for both sub periods and aggregate to obtain full period numbers. But can we combine sub-period contributions? Let's try.

Example 2

Breakdown of the preceding example into 2 sub periods (see Table 4).

Compounding the portfolio's sub periods performances provides its full period return:

$$
(1-5 \%) \times(1+11.0526 \%)-1=5.5 \% .
$$

The same is not true for position contributions. For A, $-10 \%$ and $16.84 \%$ compound to $5.16 \%$ and not $6 \%$. Summing sub period contributions (6.84\%) doesn't work either.

Why is this? Notice that a position's weight at the start of the second sub period is not just a function of its first sub period weight and performance but also of those of the other position. Splitting the analysis has introduced a cross position element which renders aggregation problematic. And this before even considering transactions!

\section{Findings and recommendations}

So, while position percentage contribution, in its simple form, is an appealing measure it is best suited for single period analysis and in the presence of transactions it is an approximation.

\subsection{Realized and Unrealized Profit and Loss}

Splitting a portfolio's profit into realized and unrealized components is a common breakdown. It's simple when the analysis starts at portfolio's opening; if not, it's tricky. This is because two timeframes are involved: the analysis period for profit and the holding period for the realized/unrealized breakdown.

Example 1

At opening, a portfolio of 100 is fully invested in a single position whose value reaches 110 at year end. At the following year end the full holding is sold for 130 . From inception to the end of the second year the portfolio's profit is 30, all of which is realized. In year one the portfolio had a profit of 10 which was unrealized. In year two the portfolio had a profit of 20 and a greater realized profit of 30 from the sale of the position. How can this be?

At the end of year one the position has an unrealized profit which has to be deducted for the second year's realized profit to reconcile with the portfolio's profit.

Table 4. Breakdown of period position contribution into that of two sub periods.

\begin{tabular}{cccccccc}
\hline \multirow{2}{*}{ Position } & \multicolumn{3}{c}{ 1st sub period } & \multicolumn{3}{c}{ 2nd sub period } & Total \\
\cline { 2 - 7 } & Weight & Perf. & Contr. & Weight & Perf. & Contr. & Perf. \\
\hline A & $50 \%$ & $-20 \%$ & $-10 \%$ & $42.1 \%$ & $40 \%$ & $16.84 \%$ & $12 \%$ \\
B & $50 \%$ & $10 \%$ & $5 \%$ & $57.9 \%$ & $-10 \%$ & $-5.79 \%$ & $-1 \%$ \\
Portfolio & $100 \%$ & $-5 \%$ & $-5 \%$ & $100 \%$ & $11.05 \%$ & $11.05 \%$ & $5.5 \%$ \\
\hline
\end{tabular}




\section{Example 2}

The 20 of profit in year two is composed of 30 realized minus 10 unrealized profit at start of year.

How should the unrealized profit at start of period be treated? This can be answered by considering that combining the analysis for year one and two should give the same result as the full period analysis (see Table 5).

We conclude that the unrealized profit at the period start should be considered as a deduction from the period's unrealized profit. This is somewhat confusing as the analysis for year two shows an unrealized loss of 10 when the portfolio holds no position at year end! To comprehend this, consider that the analysis provides the change of unrealized profit over the period rather than its absolute value.

\section{Findings and recommendations}

Explaining the breakdown, over a specific period, of a position's profit into the changes of its realized and unrealized components can be challenging. In particular the variation in a position's unrealized profit following the sale of the position is frequently counterintuitive for clients.

\subsection{Bond Yield}

For a bond, a bank statement will usually specify, in addition to the value of the position, the bond's yield to maturity. This yield corresponds to the rate at which the bond's cashflows need to be discounted so that their sum equates with the current market value of the bond.

\section{Example}

A client's banker advises investing in a new bond issue on the basis of its attractive yield. The bond is valued at 100, has a five-year maturity, pays a coupon of 5 per annum and therefore has a yield to maturity of $5 \%$ (see Table 6).

Table 5. Breakdown of period profit into realized and unrealized componenents.

\begin{tabular}{cccc}
\hline Period & Profit & Realized & Unrealized \\
\hline Since inception & 30 & 30 & 0 \\
Year one & 10 & 0 & 10 \\
Year two & 20 & 30 & -10 \\
\hline
\end{tabular}

Table 6. Present value of the bond's cashflows.

\begin{tabular}{cccc}
\hline Year & Cashflow & Discount & Present value \\
\hline 1 & 5 & $5.0 \%$ & 4.76 \\
2 & 5 & $10.3 \%$ & 4.54 \\
3 & 5 & $15.8 \%$ & 4.32 \\
4 & 5 & $21.6 \%$ & 4.11 \\
5 & 105 & $27.6 \%$ & 82.27 \\
Total & & & 100 \\
\hline
\end{tabular}


A year later the banker informs the client that the environment for bonds has improved with higher yields available and suggests increasing bond exposure. Considering this improvement, how has the $5 \%$ bond fared given its yield to maturity has risen to $6.45 \%$ (see Table 7 )?

As the bond's yield increased its price dropped to 95.03 and the client actually lost money on a mark to market basis. Thankfully, considering the coupon of 5 received in the first year she/he is just even. An environment which is described as improving for bonds purchases is actually detrimental to the valuations of previously acquired bonds.

When he acquired the bond, the client locked in the yield she/he would obtain if she/he held the bond to maturity. If yields subsequently rise his bond will appear unattractive to potential buyers and its value will fall. Alternatively, if yields fall the value of his bond will rise. But as long as the client holds the bond to maturity she/he will achieve the yield she/he locked in even if the bond's value varies with the fluctuations in yields.

\section{Findings and recommendations}

When a portfolio manager describes the environment as improving for bond purchasing it may seem unclear to the client why under such positive circumstances his current bond portfolio has been performing poorly. It is recommended to provide the client with didactic guidance on portfolio manager assertions that may create confusion and risk undermining the credibility of the reports.

\section{Conclusion}

For wealth management banks, portfolio reporting is a key channel of communication with their clients. It is therefore important that the reporting be transparent and comprehensive in nature and comprehensible to clients in order to maintain their confidence. For example, in the presence of a loan it is important to explain to the client the impact of the loan on the performance of his portfolio. A loss of a client's confidence in the reporting provided to him will convert into a more general distrust in his wealth management bank. Comprehensive reporting comes at a price, which is that the client reporting, which is based on complex mathematical calculations, becomes thus far more complicated. The possibility of including in portfolios high-end financial products such as derivatives further increases the complexity of reporting. The contribution of this paper is to specifically address some of those reporting pitfalls that regularly cause problems of understanding for clients. The pitfalls discussed in the above

Table 7. Present value of the bond's cashflows a year later.

\begin{tabular}{cccc}
\hline Year & Cashflow & Discount & Present value \\
\hline 1 & 5 & $6.45 \%$ & 4.70 \\
2 & 5 & $13.32 \%$ & 4.41 \\
3 & 5 & $20.62 \%$ & 4.15 \\
4 & 5 & $28.41 \%$ & 81.77 \\
Total & & & 95.03
\end{tabular}


sections result from:

- The impact of cashflows on performance calculations,

- The impact of loans on performance,

- Performance calculations in the presence of negative portfolio asset value,

- The consolidation of portfolio performance,

- Apparent incoherencies between portfolio performance and portfolio profit and loss,

- The breakdown of performance between realized and unrealized components,

- The relationship between bond yields and prices.

Even though the calculations upon which portfolio reporting is based are relevant and appropriate they require some accompaniment in order for the client to fully use financial reporting as a monitoring and decision aid tool to improve her/his investment strategies in the long haul. In parallel to that, clients have also, thanks to digitalization, access to new technology that enriches and complements the financial reporting provided by banks. This also can create some confusion for the client.

Nevertheless, the good thing about it is that the client is more and more involved in the management of her/his own wealth. For all these reasons, we believe that the examples we provide in this paper cover an important part of the problematic cases. They are, in the paper, articulated around the following four categories: from portfolio profit and loss to performance; details of portfolio performance calculation; portfolio consolidation and breakdown; positions performance. Each example presented corresponds to a typical pitfall that clients of wealth management face. At the end of each of these examples, we provide a comment called "findings and recommendations" that offer some elements of interpretation regarding a given pitfall and some advice for better protection of the client in the future. To maintain client trust in their reporting it is key to identify areas of potential misunderstanding prior to providing reports and offering clear explanations for the unusual numbers identified. We intend to continue this research in the future in subsequent papers to address more explanations regarding pitfalls that are not covered here. Indeed, and this is the main limitation of this paper, we investigate solely a part of the issues of actual portfolio reporting. Indeed, undeniably, it may happen that as immersed in the Swiss banking ecosystem we have addressed some pitfalls that are especially important for a given clientele. Thus, there are maybe also very important pitfalls for other countries that are not covered in that paper.

\section{Acknowledgements}

We would like to thank all our clients who have shared these issues with us.

\section{Conflicts of Interest}

The authors declare no conflicts of interest regarding the publication of this paper. 


\section{References}

Bacon, C. A. (2008). Practical Portfolio Performance Measurement and Attribution (2nd ed.). Hoboken, NJ: Wiley Publishing, Inc.

Brealey, R. A., Myers, S. C, \& Marcus, A. J. (1995). Fundamentals of Corporate Finance. New York, NY: McGraw Hill.

Brinson, G., Hood, R., \& Beebower, G. (1986). Determinants of Portfolio Performance. Financial Analysts Journal, 42, 39-44. https://doi.org/10.2469/faj.v42.n4.39

Brinson, G., Singer, B., \& Beebower, G. (1991). Determinants of Portfolio Performance II: An Up-Date. Financial Analysts Journal, 47, 40-48. https://doi.org/10.2469/faj.v47.n3.40

Christopherson, J. A., Carino, D. R., \& Ferson, W. E. (2009). Portfolio Performance Measurement and Benchmarking. New York, NY: McGraw Hill.

Feibel, B. J. (2003). Investment Performance Measurement. Hoboken, NJ: Wiley Publishing, Inc.

Grinold, R. C., \& Kahn, R. N. (2000). Active Porfolio Management: A Quantitative Approach for Providing Superior Returns and Controlling Risk. New York, NY: McGraw Hill.

Homer, S., \& Leibowitz, M. L. (1972). Inside the Yield Book. Englewood Cliffs, NJ: Prentice-Hall.

Le Sourd, V. (2007). Performance Measurement for Traditional Investment. Financial Analysts Journal, 58, 36-52.

Reilly, F. K., \& Brown, K. C. (1997). Investment Analysis and Portfolio Management (5th ed.). New York, NY: Dryden Press.

Smith, D. J. (2011). Bond Math: The Theory behind the Formulas. Hoboken, NJ: Wiley Publishing, Inc. https://doi.org/10.1002/9781118268001

Tyson, E. (1999). Investing for Dummies (5th ed.). Hoboken, NJ: Wiley Publishing, Inc. 